\title{
Total Liquid-phase Sythesis, Head-to-tail Cyclization and Synergistic Self-cleavage of Peptide on Small-molecular Supports
}

Received 00th January 20xx, Accepted 00th January 20xx DOI: $10.1039 / \times 0 \times x 00000 x$

\begin{abstract}
Haidi Li, Junyou Li, Jie Chao, Zixin Zhang, Chuanguang Qin*
To achieve the synthesis of head-to-tail cyclic peptides via the liquid-phase on-support cyclization and synergistic selfcleavage strategy, 4,4'-bis(diphenylphosphinyloxyl) diphenyl ketoxime (BDKO) and 4-diphenyl phospholoxy benzyl alcohol (DPBA) were designed and prepared as small-molecular supports for greener peptide synthesis. During liquid-phase peptide synthesis on BDKO (or DPBA) support for peptide chain extension by Boc protocol, the last amino acid at the $\mathrm{N}$-terminus of the peptide chain ends with a Fmoc protected amino acid. With the removal of the Fmoc group, head-to-tail cyclization and self-cleavage of the peptide chain synchronously occurred on BDKO (or DPBA) support to release the target cyclic peptide and the original support itself. They can be easily separated and purified, and the support can be recycled for reusing directly. The total synthesis of naturally occurring cyclic peptides such as Mortiamide A-E, Gramicidin S and cyclo(Phe-Pro) on BDKO (or DPBA) support in a resin-free manner was successfully demonstrated.
\end{abstract}

\section{Introduction}

Cyclic peptides are significant bioactive molecules that possess a wide range of biological characteristics. Compared with linear peptides, cyclic peptides are more resistant to protease hydrolysis and thus more metabolically stable. ${ }^{1}$ In addition, the spatial structure of the ring limits the conformation of cyclic peptides, increasing their binding affinity and specificity to receptors and protein targets. ${ }^{2}$ To date, chemical "de novo design" and biological "in vitro evolution" are two important ways of cyclopeptide synthesis, yet usually with low yield for preparation. Moreover, it is worth noting that as the ring size decreases, the difficulty of chemical cyclization increases..$^{1 a}$

Cyclization is the most important process in cyclopeptide formation. The conventional strategy is to prepare the linear peptides by SPPS or LPPS and utilize coupling agents (such as PyBOP/DIEA) in liquid-phase to cyclize the linear peptides ${ }^{3}$. The method is accompanied by the disadvantages of low efficiency, more by-products, difficult purification, low yield, difficult reuse and degradation of waste resin, and serious environmental pollution. So, scientists persist to improve and develop novel strategies for head-to-tail cyclization of peptides.

Previously, the on-resin cyclization/cleavage strategy was established by Qin et al to enable both the cyclization on and cleavage from the resin to proceed in the same chemical reaction and successfully apply to high-throughput synthesis of cyclopeptide libraries. ${ }^{4}$ In addition, there are also some other on-resin self-

Shaanxi Key Laboratory of Polymer Science \& Technology, OME Key Laboratory of Supernormal Material Physics \& Chemistry, School of Chemistry and Chemical Engineering, Northwestern Polytechnical University, Xi'an, 710072, P. R. China. E-mail: qinchg@nwpu.edu.cn

Electronic Supplementary Information (ESI) available: [details of any supplementary information available should be included here]. See DOI: 10.1039/x0xx00000x cyclization strategies applied to high-yield cyclic peptides synthesis. ${ }^{5-}$ 8

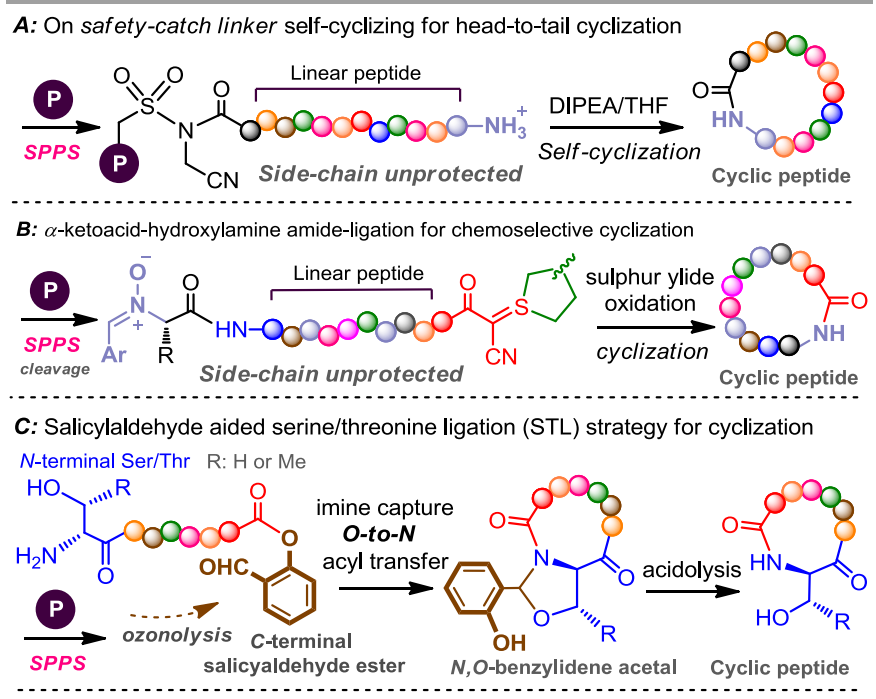

D: This Work: Ketoxime (benzyl alcohol) aided cyclization /self-cleavage strategy

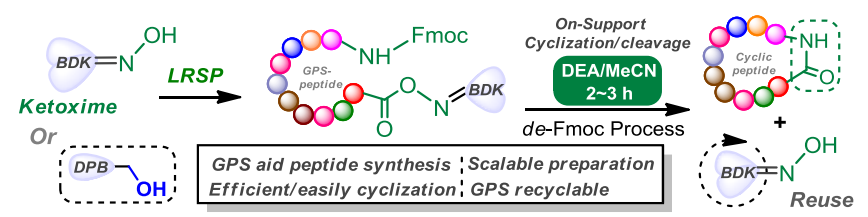

Scheme 1. The peptide head-to-tail cyclization strategies. A: SPPS-based cyclization and self-cleaving on safety-catch resin. ${ }^{4}$ B: SPPS-based peptide cyclization by Ketoacid-hydroxylamine amide-ligation strategy. ${ }^{14}$ C: SPPS-based peptide cyclization by STL protocols. ${ }^{13}$ D: Total LPPS-based cyclization and synergistic self-cleavage on small-molecular support of ketoxime (or benzyl alcohol). 
Although the difficulty in the purification of cyclic peptides has been overcome, other disadvantages still exist. Later, some of the other strategies for peptide cyclization are inspired and raised in response to the proper time and conditions, ${ }^{9}$ including ring-closing metathesis (RCM) in forming carbon-carbon bonds, ${ }^{10}$ the application of "click" chemistry to form the non-natural cyclopeptides through $\mathrm{N}$-terminal azide and C-terminal acetylene. ${ }^{11}$ It also included the specifically $O$-to- $N$ migration strategy to synthesize cyclic peptides, ${ }^{12}$ the serine/threonine ligation (STL) strategy for the synthesis of cyclopeptides teixobactin and daptomycin. ${ }^{13}$ Both the use of $\alpha$ ketoacid-hydroxylamine amide-ligation strategy for chemoselective cyclization of the side-chain unprotected linear peptides, ${ }^{14}$ and the safety-catch linker self-cyclizing strategy for head-to-tail peptide cyclization ${ }^{4}$ both are important strategies for peptide cyclization/ cleavage. Native chemical ligation (NCL) strategy has also been applied to the intramolecular cyclization for unprotected peptides with $\mathrm{N}$-terminal Cys residue. ${ }^{5}$

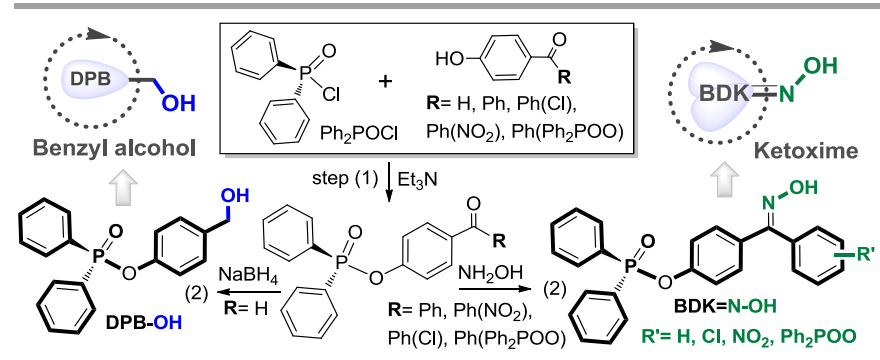

Scheme 2. The simple and high-yield two-step synthesis of $\mathrm{BDK}=\mathrm{N}-\mathrm{OH}$ supports and DPB-OH supports. [Remarked: The synthesis of BDKO supports was our previous work ${ }^{15 b}$, the synthesis of DPBA support was described in this work.]

The above cyclization strategies improved the selectivity and purity of cyclic peptides effectively, but they still rely on the resins-based heterogeneous phase synthesis. Moreover, the sequences of the cyclic peptide are strictly limited with poor generality and universality, the efficiency of cyclization and the yield of cyclopeptides are also immensely restricted. Hence, we innovated a more simplified and efficient strategy for peptide head-to-tail cyclization in homogeneous liquid-phase aided by the soluble small-molecular supports (Scheme $1 \mathbf{D}$ ). Based on our group recently reported small-molecular supports mediated Fmoc/Boc peptide synthesis and the study of support's acid-base stability ${ }^{15}$, we continue to develop the new function of $\mathrm{BDK}=\mathrm{N}-\mathrm{OH} \quad\left(4,4^{\prime}\right.$-bis (diphenylphosphinyloxyl) diphenyl ketoxime, BDKO) ${ }^{15 b}$ and $\mathrm{DPB}-\mathrm{OH}$ (4-diphenyl phospholoxy benzyl alcohol, DPBA) supports for replacing the traditional ketoxime polymer resins in peptide synthesis (Scheme 2).

\section{Results and Discussion}

We established an on-support cyclization/self-cleavage strategy for head-to-tail cyclic peptide synthesis based on BDKO or DPBA supports. On one hand, liquid-phase peptide synthesis via the Boc strategy can be performed with the aid of BDKO (or DPBA) supports. On the other hand, making full use of the acid-base stability of oxime (or benzyl) ester, which is stable to acid and unstable to base. In the process of deprotecting the $\mathrm{N}$-terminal Fmoc group of the linear peptide with DEA/MeCN system, efficiently and easily achieved intramolecular head-to-tail cyclization/ self-cleavage on BDKO (or DPBA) support to form the target cyclic peptide. At the same time, the dissociated BDKO or DPBA supports can be recycled and reused directly (Scheme 3).

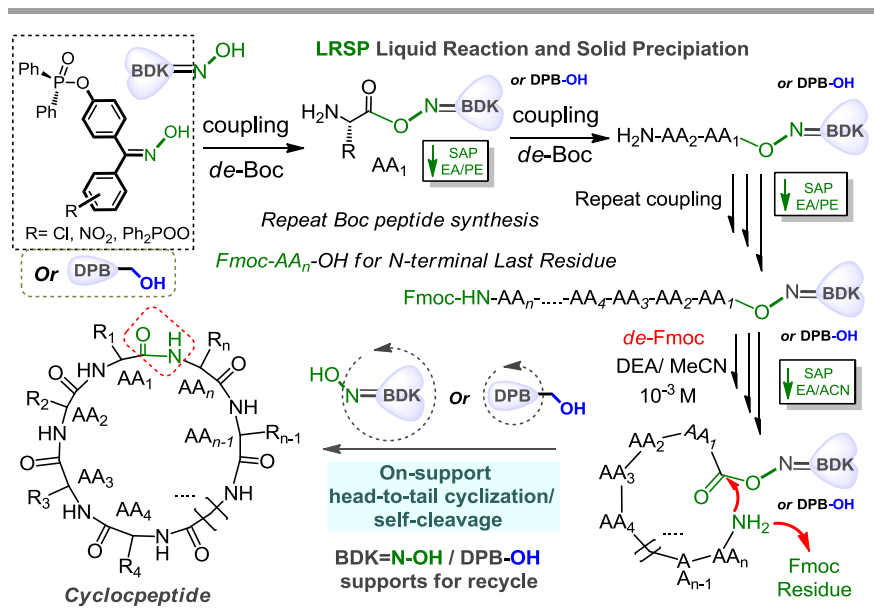

Scheme 3. Total LPPS-based cyclization and synergistic self-cleavage on small-molecular support of ketoxime (or benzyl alcohol).

Different from the heterogeneous on-resin cyclization/ cleavage for cyclopeptide synthesis, BDKO (or DPBA) supportaided protocol achieved homogeneous peptide synthesis and cyclization. Meanwhile, the cyclization/self-cleavage process can be facilely monitored by TLC analysis. The de-Fmoc process was fully utilized in replace of acetic acid-catalyzed cyclization ${ }^{7}$ to achieve the on-support cyclization/ self-cleavage, which greatly shortens the cyclization time. More inspiringly, the supports freed from cleavage can be directly recycled for reuse.

Besides BDKO (or DPBA) support mediated cyclization/selfcleavage cyclopeptide synthesis strategy was initially established, it is also necessary to verify the support-mediated Boc strategy peptide synthesis and on-support cyclization/selfcleavage method, and to further study whether spatial conformation of peptide will affect the efficiency of cyclization and the yield of cyclic peptide. In that the designed BDK=N-OH supports containing $\mathrm{NO}_{2}$ and $\mathrm{Cl}$ group are not symmetrical structures, the ketoxime supports exist as cis (or trans)-isomers. After $\mathrm{BDK}=\mathrm{N}-\mathrm{OH}\left(\mathrm{R}^{\prime}=\mathrm{NO}_{2}, \mathrm{Cl}\right)$ supports coupled with $\mathrm{Fmoc} / \mathrm{Boc}$ amino acids, TLC (or NMR) analysis manifested that the coupling products appeared obvious cis-trans isomerization, which to some extent, will affect the accuracy of chromatographic analysis for peptide intermediates. The studies show that the introduction of electron-withdrawing groups $\left(\mathrm{R}^{\prime}=\mathrm{NO}_{2}, \mathrm{Cl}\right)$ on ketoxime supports have little effect on the overall acid-base stability of the formed oxime-ester after BDKO were coupled with amino acids. Therefore, $\mathrm{BDKO}\left(\mathrm{R}^{\prime}=\mathrm{NO}_{2}, \mathrm{Cl}\right)$ was not the optimal supports for peptide synthesis. While $B D K=N-O H\left(R^{\prime}=\right.$ $\mathrm{Ph}_{2} \mathrm{POO}$ ) does not show cis-trans isomerism after coupled with amino acids, hence the symmetrical $\mathrm{BDKO}\left(\mathrm{R}^{\prime}=\mathrm{Ph}_{2} \mathrm{POO}\right)$ was selected as the support for head-to-tail cyclization/ cleavage cyclopeptide synthesis. 
$\mathrm{BDK}=\mathrm{N}-\mathrm{OH} \quad\left(\mathrm{R}^{\prime}=\mathrm{Ph}_{2} \mathrm{POO}\right)$ support mediated Boc strategy peptide synthesis was preliminarily carried out to verify the feasibility of the head-to-tail cyclization/self-cleavage method and the influence of amino acid configuration on cyclization. Hexapeptide FVFVFV was accordingly selected as the template peptide for peptide chain elongation, and on-support head-totail cyclization/ self-cleavage for FVFVFV was tentatively attempted. On one hand, cyclopeptide cyclo(FVFVFV) is a demethylamidated cyclopeptide analog of natural cyclic ester peptide Beauvericin, ${ }^{16}$ and its cyclization is of great significance for the synthesis of Beauvericin analogs. On the other hand, the FVFVFV chain is prone to gelation in traditional LPPS, while in SPPS the peptide chain shows the inclination to adhere to the resin beads and locally terminate the extension of the peptide chain, which will lead to the complexity of peptide products and thus hamper the yield. (Scheme 4A).

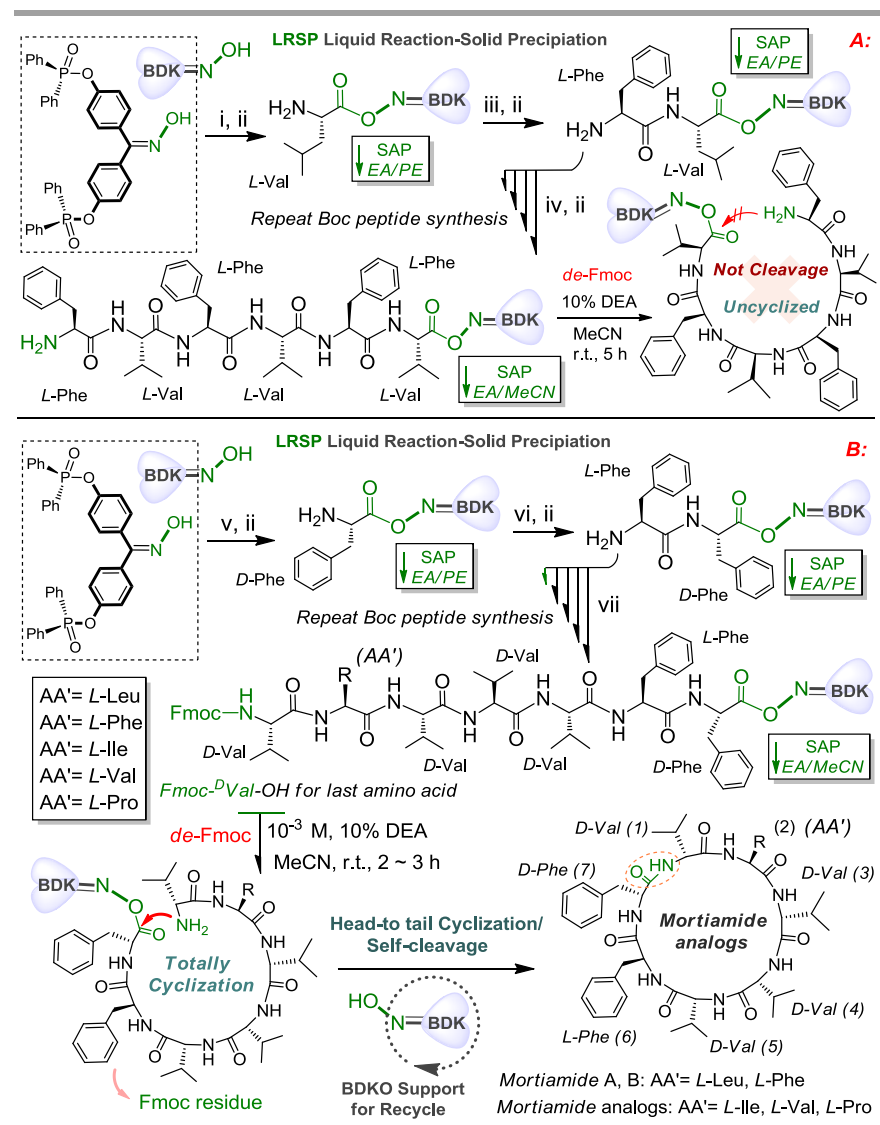

Scheme 4. BDKO-aided total liquid-phase synthesis of cyclopeptides. A: Synthesis of hexapeptide FVFVFV and it's onBDKO cyclization/self-cleavage attempts. Condition: i: Boc- ${ }^{-} \mathrm{Val}-$ OH, EDCl/DMAP, DCM, r.t., 1 h; ii: 50\% TFA/DCM ( $v / v, 1: 1$, TFA: 99.9\%), $0{ }^{\circ} \mathrm{C}, 1 \mathrm{~h}$; iii: Boc- ${ }^{-}$Phe-OH, EDCl/HOBt/DIEA (2.0 eq), DCM, r.t., $1 \mathrm{~h}$; iv: Repeat peptide synthesis; B: On-BDKO cyclization/self-cleavage for synthesis of Mortiamide analogs. Condition: v: Boc- ${ }^{-}$Phe-OH, EDCl/DMAP, DCM, r.t., 1 h; vi: BocLPhe-OH, EDCl/HOBt/DIEA (2.0 eq), DCM, r.t., 1 h; vii: Repeat peptide synthesis, Fmoc- ${ }^{D}$ Val-OH for last amino acid.

Boc- ${ }^{-}$Val-OH was firstly loaded onto $\mathrm{BDK}=\mathrm{N}-\mathrm{OH}\left(\mathrm{R}^{\prime}=\mathrm{Ph}_{2} \mathrm{POO}\right)$ by EDCl/DMAP coupling system, Boc group was then removed by $50 \%$ TFA/DCM ( $v / v, 1: 1,0{ }^{\circ} \mathrm{C}$, TFA: $\left.99.9 \%\right)$ to obtain TFA.H-LVal-O-N=BDK. Then, the second Boc- ${ }^{-} \mathrm{Phe}-\mathrm{OH}$ was coupled to BDKO support by
EDCl/HOBt/DIEA ( 2.0 eq) coupling system to derive Boc-LPhe-LVal-O$\mathrm{N}=\mathrm{BDK}$. It is worth noting that as TFA.H-Val-O-N=BDK exists in the form of TFA salts, the add of DIEA in the coupling reagent system was twice equivalent of $\mathrm{H}-{ }^{-} \mathrm{Val}-\mathrm{O}-\mathrm{N}=\mathrm{BDK}$ so as to neutralize the TFA. According to the above coupling and de-Boc conditions, the next four $L$-amino acids were coupled by EDCl/HOBt/DIEA (2.0 eq) coupling system to derive BDKO-attached hexapeptide chain $\mathrm{H}^{-}{ }^{-} \mathrm{Ph}{ }^{-}{ }^{-} \mathrm{Val}-$ LPhe- ${ }^{L}$ Val--LPhe-LVal-O-N=BDK.

Then, $10 \% \operatorname{DEA} / \mathrm{MeCN}(v / v, 1: 9)$ was used for conducting the onBDKO support cyclization/self-cleavage for the FVFVFV chain to substantiate the possibility of head-to-tail cyclization. In order to avoid the formation of the dimer (or polymer) by intermolecular aggregation of FVFVFV, on-BDKO cyclization/ self-cleavage procedure was maintained in sparse concentration $\left(10^{-3} \mathrm{M}\right)$. However, even with many attempts, the target cyclo(FVFVFV) still could not be obtained through the above cyclization condition, which might be ascribed to that FVFVFV containing Val and Phe were alternately connected by L-configuration, so the whole peptide chain does not fold or bend in space to form the preferred conformation of cyclization. Furthermore, there is no 6 -turn proline (Pro) and flexible glycine (Gly) in the linear peptide, prodigiously challenging the cyclization. (Scheme 4A).

To increase the possibility of on-BDKO support cyclization/ self-cleavage, it is required to enlarge the proportion of $D$ amino acids in peptide chains or introduce the 8 -turn Pro and flexible Gly. Only in this way can the peptide chains realize the on-BDKO cyclization/ self-cleavage to form the cyclic peptides. Mortiamide A, B, containing the $L(D)$-configurational chains and aromatic amino acids, were head-to-tail cyclopeptides isolated from Mortierella. sp. ${ }^{17}$ and previously synthesized by ketoxime resins. ${ }^{7 a}$ Therefore, Mortiamide A, B, and their analogs were selected as template peptides to corroborate on-BDKO cyclization/self-cleavage for cyclopeptide synthesis.

Referring to the above BDKO mediated Boc peptide synthesis procedures, we preliminarily synthesized the linear hexapeptide TFA $\cdot{ }^{-}-{ }^{-}$Leu- ${ }^{D}$ Val- ${ }^{D}$ Val- ${ }^{D}$ Val- ${ }^{-}$Phe- ${ }^{D}$ Phe-O-N=BDK, then $\mathrm{Fmoc}-{ }^{D} \mathrm{Val}-\mathrm{OH}$ was coupled as a terminal amino acid to terminate the peptide chain and derive Fmoc- $D$ Val-Leu- $D$ Val${ }^{D}$ Val- $D$ Val-Phe- ${ }^{D}$ Phe-O-N=BDK with $42 \%$ total yield. In the same way, without changing the amino acid configuration, we prepared the linear peptide analogs Fmoc-DVal-LAA'-DVal-DVal-

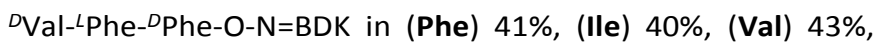
(Pro) $41 \%$ total yields respectively. The BDKO attached peptide chains can be primely precipitated and purified in the ethyl acetate/ acetonitrile precipitation system. (Scheme 4B)

Afterwards, $10 \% \mathrm{DEA} / \mathrm{MeCN}\left(v / v, 1: 9,10^{-3} \mathrm{M}\right)$ cyclization reagent was used to conduct on-BDKO support cyclization/selfcleavage for heptapeptide chains, upholding the head-to-tail cyclization. In this way, $c y c l o\left({ }^{D}\right.$ Val- ${ }^{-}$Leu- ${ }^{D}$ Val- ${ }^{D}$ Val- ${ }^{-}$Val-- ${ }^{-}$Phe${ }^{D}$ Phe), $\quad c y c l o\left({ }^{D}\right.$ Val-LPhe- ${ }^{D}$ Val-- ${ }^{D}$ Val- ${ }^{D}$ Val-LPhe- ${ }^{D}$ Phe), $\quad c y c l o\left({ }^{D}\right.$ Val-

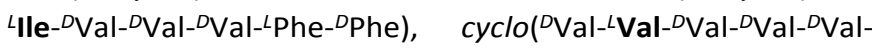
${ }^{L}$ Phe-- $D$ Phe), and $c y c l o\left({ }^{D}\right.$ Val-LPro- ${ }^{D}$ Val- ${ }^{D}$ Val-- ${ }^{D}$ Val-LPhe- ${ }^{D}$ Phe) were successfully obtained with $92 \%, 91 \%, 89 \%, 85 \%$ and $92 \%$ yields respectively. Noteworthily, all the cyclic heptapeptides were cyclized completed within 2 3 h, and the cyclization efficiency is much higher than that of on-resins cleavage or traditional coupling reagents. (Scheme 4B and Table 1) 


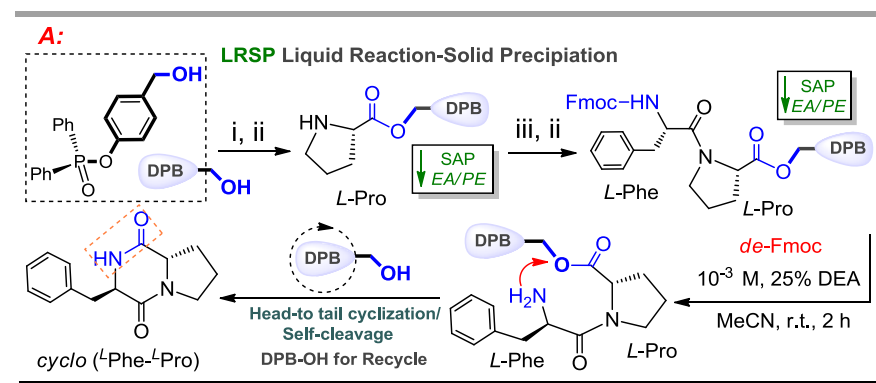

(1)

Scheme 5. DPBA-aided total liquid-phase synthesis of cyclopeptides. A: On-DPBA cyclization and self-cleavage for synthesis of cyclic dipeptide. Condition: i: Boc-LPro-OH, EDCl/DMAP, DCM, r.t., 1 h; ii: $50 \%$ TFA/DCM $(v / v, 1: 1), 1$ h. iii: Fmoc-LPhe-OH, EDCl/HOBt/DIEA (2.0 eq), DCM, r.t., 1 h. B: Synthesis of linear gramicidin S and it's on-DPBA cyclization/ self-cleavage attempts. iv: Boc-LLeu-OH, EDCl/ DMAP, DCM, r.t., 1 h; v: Boc-LOrn(Fmoc)-OH, EDCl/HOBt/DIEA (2.0 eq), DCM, r.t., $1 \mathrm{~h}$; vi: Repeat Boc peptide synthesis, Fmoc- ${ }^{D} \mathrm{Phe}-\mathrm{OH}$ for last amino acid.
On-DPBA cyclization and self-cleavage for cyclopeptide synthesis can be carried out as well. The esters formed by DPB$\mathrm{OH}$ with amino acids were significantly more stable to the organic base (DEA or Pip) than the oxime esters formed by $B D K=N-O H$ support with amino acids.

First, the short-chain dipeptide was synthesized by DPB-OH support to validate the possibility of cyclization/ self-cleavage. Similarly, according to the above EDCI/DMAP, EDCl/HOBt/ DIEA coupling reagents system, and coupling procedures, we successfully derived the DPB-OH attached linear dipeptide Fmoc-LPhe-LPro-O-DPB in $88 \%$ total yield. Then, $25 \%$ DEA/ $\operatorname{MeCN}\left(v / v, 1: 3,10^{-3} \mathrm{M}\right)$ was used to remove the Fmoc group of Fmoc-LPhe-LPro-O-DPB, meanwhile, the cyclic dipeptide cyclo ('Phe-LPro) was thus obtained with $84 \%$ yield through the headto-tail cyclization /self-cleavage method. (Scheme 5A)

To confirm the feasibility of the on-DPBA support cyclization/ self-cleavage method in the synthesis of long-chain cyclic peptides, the representative cyclic decapeptide gramicidin $\mathrm{S}$ was thus selected as the template cyclopeptide. According to the above EDCl/DMAP and $\mathrm{EDCl} / \mathrm{HOBt} / \mathrm{DIEA}$ coupling reagents system, we preliminarily procured the $\mathrm{H}^{-} \mathrm{O} \mathrm{Orn}(\mathrm{Fmoc})-{ }^{-} \mathrm{Leu}-\mathrm{O}-\mathrm{DPB}$ in almost equivalent yield. Then, we continued to extend the peptide chain $\mathrm{H}^{-}{ }^{\mathrm{L} O r n}(\mathrm{Fmoc}){ }^{-} \mathrm{L}$ LeuO-DPB by Boc synthesis strategy and EDCl/HOBt/DIEA coupling reagents to derived the $\mathrm{Fmoc}-{ }^{-} \mathrm{Phe}-\mathrm{OH}$ as last amino acid terminated

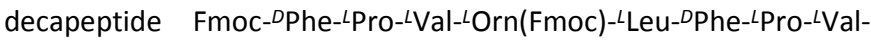
LOrn (Fmoc)-Leu-O-DPB in $61 \%$ total yield. After that, $25 \%$ $\mathrm{DEA} / \mathrm{MeCN}\left(v / v, 1: 3,10^{-3} \mathrm{M}\right)$ cyclization reagent was applied to implement the on-DPBA support cyclization/ self-cleavage for linear gramicidin S. However, under such condition, there is no head-to-tail cyclization/self-cleavage product gramicidin $\mathrm{S}$ produced. Even by raising the self-cleavage temperature to $45{ }^{\circ} \mathrm{C}$, and assisting the process with ultrasonic, we still could not get the target cyclic decapeptide gramicidin $\mathrm{S}$. Herein, only the de-Fmoc group product

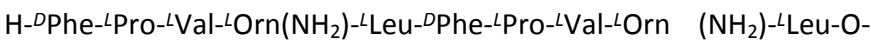
DPB was obtained. (Scheme 5B)

Table 1. The results of cyclopeptide synthesis mediated by BDKO (or DPBA) support.

\begin{tabular}{|c|c|c|c|c|}
\hline entry & peptide name & cyclopeptides sequence & cyclization yield & cyclization time $(\mathrm{h})$ \\
\hline 1 & Beauvericin analog $a$ & cyclo(LPhe-LVal-LPhe-LVal-LPhe-LVal) & $\mathbf{0}^{a}$ & $>5.0^{a}$ \\
\hline 2 & Mortiamide $\mathrm{A}^{a}$ & $c y c l o(D$ Val-LLeu-DVal-DVal-DVal-LPhe-DPhe) & $92 \%$ & 2.5 \\
\hline 3 & Mortiamide $\mathrm{B}^{a}$ & cyclo( ${ }^{D}$ Val--LPhe-- ${ }^{D}$ Vpl- ${ }^{D}$ Val-- $D$ Val-LPhe- ${ }^{D}$ Phe) & $91 \%$ & 2.0 \\
\hline 4 & Mortiamide $\mathrm{C}^{a}$ & $c y c l o\left({ }^{D}\right.$ Val--Lle-- ${ }^{D}$ Val- ${ }^{D}$ Val-DVal--LPe- ${ }^{D}$ Phe) & $89 \%$ & 2.5 \\
\hline 5 & Mortiamide $\mathrm{D}^{a}$ & $c y c l o\left({ }^{D}\right.$ Val-LVal-DVal-DVal-DVal-LPhe-DPhe) & $85 \%$ & 3.0 \\
\hline 6 & Mortiamide $\mathrm{E}^{a}$ & cyclo( ${ }^{D}$ Val-LPro- ${ }^{D}$ Val-- ${ }^{D}$ Val-- ${ }^{D}$ Val-LPhe- ${ }^{D}$ Phe) & $92 \%$ & 2.0 \\
\hline 7 & Cyclic dipeptide ${ }^{b}$ & cyclo('LPhe-LPro) & $84 \%$ & 4.0 \\
\hline 8 & Gramicidin $\mathrm{S}^{c}$ & 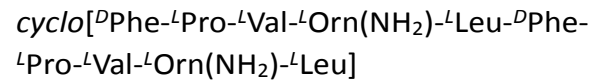 & $52 \%{ }^{c}$ & $16.0^{c}$ \\
\hline
\end{tabular}

Condition: ${ }^{a}$ On-BDKO support cyclization and self-cleavage strategy. ${ }^{b}$ On-DPBA support cyclization and self-cleavage strategy. ${ }^{c}$ Cyclization by traditional PyBOP/DIEA coupling reagents.

The traditional coupling reagent aided cyclization for the synthesis of gramicidin $\mathrm{S}$ was further probed as a comparison with the on-support cyclization/self-cleavage. After cleaving de-Fmoc linear decapeptide H-DPhe-LPro-LVal-LOrn $\left(\mathrm{NH}_{2}\right)$-Leu-DPhe-LPro-LValLOrn $\left(\mathrm{NH}_{2}\right.$ )- ${ }^{-}$Leu-O-DPB by LiOH (or TFA/Tis/ $/ \mathrm{H}_{2} \mathrm{O}$ ) reagents, the headto-tail cyclization of linear decapeptide was hence carried out 
through the PyBOP/DIEA cyclization reagent system. In this way, we successfully derived the target cyclo (DPhe-Pro-Val-Orn-Leu-DPhePro-Val-Orn-Leu) in a $52 \%$ yield. It is noteworthy that this cyclization method requires 16-24 hours to achieve the maximum cyclization of gramicidin S. Meanwhile, the coupling reagent was difficult to separate thoroughly from the cyclic peptide, becoming a sharp contrast to the on-support cyclization strategy. (Scheme 5B and Table 1) The fact that the long-chain gramicidin $S$ could not implement the on-DPBA cyclization/self-cleavage, can boil down to that with the extension of the peptide chain, the increasing amide groups, especially the $\mathrm{NH}_{2}$ group on Orn side chains make the whole peptide chain liable to form strong intermolecular and intramolecular hydrogen bonds. The intramolecular strong aggregation effect increased the steric hindrance of the whole peptide system, obstructing the cleavage of DPBA support by organic bases (such as DEA) accurately.

\section{Conclusions}

In conclusion, we successfully established the BDKO (or DPBA) small-molecular supports-mediated homogeneous phase onsupport cyclization and synergistic self-cleavage protocol for cyclopeptide synthesis. After self-cleavage of the peptides, ketoxime (or benzyl alcohol) supports can be directly recycled for reuse. In addition, this protocol avoids the involvement of cyclization reagents, and the synthesis process is homogeneous, which maximumly saved the raw materials and reagents, and reduced the process mass intensity (PMI) which is an important green index ${ }^{18}$ in the chemistry of organic synthesis and industrial process. Therefore, greening and efficient cyclopeptide preparation can be achieved through this synthesis-to-cyclization strategy. This small-molecular supports mediated on-BDKO (or DPBA) cyclization and synergistic selfcleavage strategy can be anticipated to provide a new sight for the cyclization of peptides in the liquid phase and looks to be extended to the field of the synthesis of more extensive cyclic peptides, even encompassing the non-peptide cyclic molecules. On the other hand, the vital challenge of peptide synthesis is hard to produce peptides on a large scale and environmentfriendly for industrialization, because of limitations such as low loading value on resin, much excessive consumption of raw materials and solvents, high PMI, and large-amount of unreusable and undegradable waste-resin pollutant in solidphase peptide synthesis. Development innovation of simplified, efficient, and scale-adjustable novel liquid phase peptide synthesis strategy is still the worthy focus of scientists in the future.

\section{Data Availability}

All data are available in the ESI.

\section{Author Contributions}

Prof. C. G. Qin initiated and designed the entire research. The manuscript was written by H. D. Li and J. Y. Li, and revised by C. G. Qin. H. D. Li, J. Chao, Z. X. Zhang participated in the entire experiment.

\section{Conflicts of interest}

There are no conflicts to declare.

\section{Acknowledgements}

This work was supported by the National Natural Science Foundation of China (21572180), the Intergovernmental Science and Technology Cooperation and Exchange Program between China and Romania (43-24-20180510), the National College Students' Innovation and Entrepreneurship Training Program of China. We gratefully acknowledge the Analytical \& Testing Center of Northwestern Polytechnical University for the NMR analysis.

\section{Notes and references}

1 (a) A. J. Cameron, K. G. Varnava, W. A. Denny and G. Sanjayan, Chem. Rev., 2019, 119, 10318-10359. (b) P. G. Dougherty, A. Sahni and D. H. Pei, Chem. Rev., 2019, 119, 10241-10287. (c) D. S. Nielsen, N. E. Shepherd, W. J. Xu, A. J. Lucke, M. J. Stoermer and D. P. Fairlie, Chem. Rev., 2017, 117, 8094-8128. (d) R. J. Brea, C. Reiriz and J. R. Granja, Chem. Soc. Rev., 2010, 39, 1448-1456.

2 L. Reguera and D. G. Rivera, Chem. Rev., 2019, 119, 9836-9860.

3 (a) Y. Onda, Y. Masuda, M. Yoshida and T. Doi, J. Med. Chem., 2017, 60, 6751-6765. (b) P. Barbie and U. Kazmaier, Org. Biomol. Chem., 2016, 14, 6036-6054.

4 (a) C. G. Qin, X. Z. Bu, X. M. Wu and Z. X. Guo, J. Comb. Chem., 2003, 5, 353-355. (b) C. G. Qin, X. F. Zhong, X. Z. Bu, N. L. J. Ng and Z. X. Guo, J. Med. Chem., 2003, 46, 4830-4833. (c) C. G. Qin, X. Z. Bu, X. F. Zhong, N. L. J. Ng and Z. X. Guo, J. Comb. Chem., 2004, 6, 398-406.

5 (a) G. Serra, L. Posadaa and H. Hojo, Chem. Commun., 2020, 56, 956-959. (b) J. Tulla-Puche and G. Barany, J. Org. Chem., 2004, 69, 4101. (c) B. H. Gless and C. A. Olsen, J. Org. Chem., 2018, 83, 10525.

6 Ahsanullah and J. Rademann, Angew. Chem. Int. Ed., 2010, 49, 5378-5382.

7 (a) C. Berube, D. Gagnon, A. Borgia, D. Richard and N. Voyer, Chem. Commun., 2019, 55, 7434-7437. (b) C. Bérubé, A. Borgia and N. Voyer, Org. Biomol. Chem., 2018, 16, 9117-9123. (c) C. Bérubé, A. Borgia and N. Voyer, Tetrahedron Lett., 2018, 59, 4176-4179. (d) T. Tremblay, G. Robert-Scott, C. Berube, A. Carpentier, N. Voyer and D. Giguere, Chem. Commun., 2019, 55, 13741-13744.

8 M. Tamaki, K. Honda, S. Kikuchi and R. Ishii, Tetrahedron Lett., 2006, 47, 8475-8478.

9 C. J. White and A. K. Yudin, Nat. Chem., 2011, 42, 509-524.

10 (a) S. J. Miller, H. E. Blackwell and R. H. Grubbs, J. Am. Chem. Soc., 1996, 118, 9606-9614. (b) H. E. Blackwell and R. H. Grubbs, Angew. Chem. Int. Ed., 1998, 37, 3281-3284.

11 (a) V. D. Bock, R. Perciaccante, T. P. Jansen, H. Hiemstra and J. H. van Maarseveen, Org. Lett., 2006, 8, 919-922. (b) J. H. van Maarseveen, W. Seth Horne and M. Reza Ghadiri, Org. Lett., 2005, 57, 4503-4506.

12 (a) J. Lécaillon, P. Gilles, G. Subra, J. Martinez and M. Amblard, Tetrehedron Lett., 2008, 49, 4674-4676. (b) W. D. F. Meutermans, S. W Golding, G. T. Bourne, L. P. Miranda, M. J. 
Dooley, P. F. Alewood and M. L. Smythe, J. Am. Chem. Soc., 1999, 121, 9790-9796.

13 (a) C. T. T. Wong, H. Y. Lam, T. Song, G. H. Chen and X. C. Li. Angew. Chem. Int. Ed., 2013, 125, 10402-10405. (b) H. Liu and X. C. Li, Acc. Chem. Res., 2018, 51, 1643. (c) K. Jin, I. H. Sam, K. H. L. Po, D. A. Lin, E. H. Ghazvini Zadeh, S. Chen, Y. Yuan and X. C. Li, Nat. Commun., 2016, 7, 12394. (d) H. Y. Lam, Y. F. Zhang, H. Liu, J. C. Xu, C. T. T. Wong, C. Xu and X. C. Li, J. Am. Chem. Soc., 2013, 135, 6272-6279.

14 T. Fukuzumi, L Ju and J. W. Bode. Org. Biomol. Chem., 2012, 10, 5837-5844.

15 (a) H. D. Li, J. Chao, G. Tian, J. Hasan, Y. T. Jin, Z. X. Zhang and C. G. Qin, Org. Chem. Front., 2020, 7, 689. (b) H. D. Li, J. Chao, Z. X. Zhang, G. Tian, J. Li, N. H. Chang and C. G. Qin, Org. Lett., 2020, 22, 3323-3328. (c) H. D. Li, J. Chao, J. Hasan, G. Tian, Y. T. Jin, Z. X. Zhang and C G. Qin, J. Org. Chem., 2020, 85, 62716280. (d) H. D. Li, J. Ren, J. Y. Li, Z. X. Zhang, N. H. Chang and C. G. Qin, Org. Biomol. Chem., 2020, 18, 8433-8442.

16 R. L. Hamill, C. E. Higgens, H. E. Boaz and M. Gorman, Tetrahedron Letters., 1969, 10, 4255-4258.

17 A. L. Grunwald, F. Berrue, A. W. Robertson, D. P. Overy and R. G. Kerr, J. Nat. Prod., 2017, 80, 2677-2683.

18 A. Isidro-Llobet, M. N. Kenworthy, S. Mukherjee, M. E. Kopach, K. Wegner, F. Gallou, A. G. Smith and F. Roschangar, J. Org. Chem., 2019, 84, 4615-4628. 